\title{
Adaptation of the Relationship and Motivation Scale to the Turkish Culture
}

\author{
Munevver Ilgun Dibek ${ }^{1}$, Hatice C Yavuz ${ }^{1}$, Ezel Tavsancil ${ }^{1} \&$ Seher Yalcin $^{1}$ \\ ${ }^{1}$ Department of Educational Sciences, Ankara University, Ankara, Turkey \\ Correspondence: Munevver Ilgun Dibek, Department of Educational Sciences, Ankara University, Cebeci \\ Campus, Ankara, 06590, Turkey. E-mail: milgun@ankara.edu.tr
}

Received: March 28, 2017

Accepted: April 12, $2017 \quad$ Online Published: April 16, 2017

doi:10.5539/jel.v6n3p181

URL: http://doi.org/10.5539/jel.v6n3p181

\begin{abstract}
The purpose of the present study was twofold: first to adapt the Relationship and Motivation (REMO) scale addressing role of peers and teachers in students' motivations into Turkish culture, and second to determine whether there were any differences between girls and boys regarding the scores obtained from this scale. To achieve these aims, the present research was designed to be comprised of three consecutive studies. In Study 1, linguistic equivalence was established, and results of an Explanatory Factor Analysis (EFA) performed on data obtained from 202 students showed that structure of the original scale was supported. In Study 2, a Confirmatory Factor Analysis (CFA) was conducted using data obtained from 496 Turkish students, and the results confirmed the results of EFA. Additionally, the validity evidence was obtained by conducting another EFA with 528 students. Moreover, reliability coefficients were also found to be varying in an acceptable range. Including the same participants of Study 2 in Study 3, t-test results showed that girls had significantly higher mean scores on the subscales of peers and teachers as positive motivators, and teachers as negative motivators. On the other hand, boys had significantly higher mean scores on the scale of peers as negative motivators. Results of these studies suggest that Turkish version of REMO is conceptually equivalent to original REMO, and similarly reliable and valid. Therefore, the adapted scale can not only be used in cross-cultural comparison and but also for determining the differentiation in the relations of students with their peers and teachers.
\end{abstract}

Keywords: individual learning, motivation, scale adaptation, sex differences, peer relations, teacher relations

\section{Introduction}

Most theories of motivation (e.g., cognitive attribution theory of motivation and emotion [CATME; Weiner, 1972], achievement goal theory [AGT; Elliot, 1997], and self-determination theory [SDT; Deci \& Ryan, 1985]) focus on factors related to achievement-oriented behaviors. According to SDT, individuals are self-motivated and willing to succeed. However, this theory assumes that some people may be amotivated due to the social environments with which they interact (Deci \& Ryan, 2008). Self-determination theory refers to three fundamental needs, namely competence, autonomy, and relatedness to others (Deci \& Ryan, 2000). If the social context satisfies these needs, this will encourage individuals to be active and increase their motivation resulting in positive psychological and behavioral outcomes (Ryan \& Deci, 2000). On the other hand, if the social environment fails to address these needs, motivation may be adversely affected. Within the educational context, one of the social environments is school where classmates and teachers may affect students' motivation and engagement (Reeve, 2006).

Adolescent students tend to think that their peers understand them better than their families and therefore, they make an effort to be a natural part of their peer group and to be liked by their peers (Kiran-Esen, 2013). A peer may be defined as "an identical person in terms of specific qualities such as skills, success level, age, past and socio-economical level” (Reber A. \& Reber E., 2001, p. 518). During adolescence, certain social needs such as sense of belonging, acceptance, social approval, and bonding are experienced more intensely and affected by young individuals' peer group (Aydın, 2008). Student-student interaction plays a key role in helping students become socialized, avoid anti-social behaviors, shape students' mental health, develop their sexuality, understand others better (empathy), avoid self-centeredness, increase their willingness to continue their education and have better academic success (Krunke \& Raufelder, 2014; Y1lmaz, 2001). It has been reported that peer relations are particularly important to students' academic success (Ladd, Herald-Brown, \& Kochel, 2009). In addition, 
students' relations with their peers play a role in their academic motivation (Juvonen \& Wentzel, 1996; Ladd et al., 2009; Reindl, Berner, Scheunpflug, Zeinz, \& Dresel, 2015; Wentzel, Battle, Russell, \& Looney, 2010). On the other hand, among learning theories, those of Kolb (1984) and Keen and Mahanty (2006) place emphasis on individual learning (Armitage, Marschke, \& Plummer, 2008). To increase academic success, teachers who implement alternative learning methods have discovered that some of their students are more successful both individually and in comparison with their peers (Dunn \& Honigsfeld, 2013).

Since the student-teacher relation affects students' psychological and cognitive characteristics in various ways, motivation theories have emphasized that students' perception of their relationship with their teacher has an impact on their performance (Fan \& Willams, 2010; Ryan, Stiller, \& Lynch, 1994). In particular, attachment theory emphasizes the influence of student attachment to school (Bowlby, 1969; Bretherton, 1987), and social support models focus on students' social skills as well as skills of coping with problems (Sarason, Sarason, \& Pierce, 1990), and Ryan and Deci (2000) have emphasized that student-teacher relations affect students' social and academic participation. Thus, there is a consensus among researchers that the quality and nature of the student-teacher relationship plays an important part in students' learning motivation (Becker \& Luthar, 2002; Pianta, Hamre, \& Stuhlman, 2003; Skinner \& Belmont, 1993).

Researchers have also found sex differences in academic motivation (Csizér \& Dörnyei, 2005; Karsenti \& Thibert, 1994; Kissau, 2006; Meyer, Weir, McClure, Walkey, \& McKenzie, 2009; Thibert \& Karsenti, 1996; Thibert \& Karsenti, 1998; Watt, 2004). The nature of teacher-student relation affects students' motivation and achievement based on the sex of the students. Several studies (Saft \& Pianta, 2001; Silver, Measelle, Armstrong, \& Essex, 2005) have shown that as opposed to girls, boys' relationships with their teachers are defined by less closeness and more conflict. This is because boys have a tendency to disobey rules as well as being more self-regulated than girls (Hughes \& Kwok, 2006). However, there is no consensus between these researchers concerning how or why this relationship is observed.

Given the crucial role of students' relations with their teachers and peers in their motivation and achievement, defining these relationships and students' motivation would provide information necessary for understanding students and their education, which are the main focus of education. These relationships have a significant role in all cultures, in particular those that are collectivistic (Trumbull \& Rothstein-Fisch, 2011). This is because in collectivistic societies, connectedness among members of groups is highly valued (Rhee, Uleman, \& Lee, 1996; Zhang, Chen, Greenberger, \& Knowles, 2017) whereas in individualistic societies, autonomy, independence, and individualized relationships are important (Hofstede, 1980). Therefore, the link between these relationships and motivation also varies with respect to different cultures. In fact, motivation is "no longer an individual construct, but one that is shaped by the cultural, social and educational context in which the learner is operating" (Engin \& McKeown, 2012, p. 2). More specifically, in educational settings, students from Eastern collectivistic societies tend to be more socio-motivationally dependent on their relations in class (Chiu \& Chow, 2010) whereas students in Western individualistic societies depend less on these relationships in terms of their motivation (Hesse, 2004). To effectively identify such relationships with different patterns in different cultures, various measurements are used.

In Turkey, there is no scale that measures the role of both teachers and peers on students' relations and determines how these relations vary according to students' sex; therefore, there is an essential need to establish a valid and reliable measurement tools that will address the relations of students in the Turkish culture. This study aimed to fill this gap in the literature by adapting the REMO scale (Raufelder, Drury, Jagenow, Hoferichter, \& Bukowski, 2013) which is a valid and reliable measurement tool into Turkish culture. This scale was designed to identify the relationships of German students aged 11 to 17 years with their peers and teachers as well as their academic motivation. Given that socio-motivational dependency on teachers and peers varies depending on potential differences between cultural contexts, adaptation of a scale that was originally developed for a Western culture, namely German, to an eastern culture may also provide contribution to understanding about how these relations are established in individualistic and collectivistic societies.

To obtain valid and reliable measurement tool which can provide realistic results about the role of teachers and peers on students' academic motivation in different culture, this research was divided into three studies; (1) Study 1 aimed to adapt REMO to the Turkish culture, establish linguistic equivalence, and determine the clarity of the adapted items and whether they have the same factor structure as in the original scale; (2) Study 2 aimed to determine validity and reliability of the Turkish version of the scale, and (3) Study 3 aimed to test whether measurement invariance across sex was established, and to determine whether there were any differences between the two groups of adolescents (boys and girls) in terms of their scores from this scale. 


\section{Study 1}

\subsection{Method}

\subsubsection{Participants}

For the evaluation of the linguistic equivalence between the original and Turkish versions of the scale, both measures were administered to 20 Turkish students enrolled in a university where the language of instruction is English at one-week intervals. The reason why the scale was applied to a different student group for the analysis of equivalence was because none of the students in the sample group had a sufficient level of English.

A pilot study was conducted with 202 Turkish students from public schools using purposive sampling. In the sampling process, students were recruited by considering the characteristics of the sample that was administered the original scale, e.g., regarding age range. Therefore, for the pilot study, the adapted scale was administered to the students aged 11 to 16 years. Additionally, the number of the students from different sexes was balanced in the pilot study (110 girls, 92 boys).

In this study, the students' participation was voluntary. Prior to the data collection, permissions were obtained from the appropriate authorities. During the collection process, the students were informed that their responses would be kept confidential. In order not to intervene with the natural atmosphere of the class, the class teachers administered the measures after being instructed about the standards of the data collection process. Data were obtained on different days depending on the availability of teachers and students.

\subsubsection{Measure}

In this study, the original REMO and its Turkish adaptation were used. The original REMO (Raufelder et al., 2013), which was designed for a German sample, is a four-point Likert scale with 37 items categorized under two sub-scales; namely, Peer REMO (P-REMO) and Teacher REMO (T-REMO) containing three and two factors, respectively. Moreover, original REMO has both English and German versions. Overall, Turkish version of REMO was adapted from English version. The reliability results of the original scale are given in Table 1.

Table 1 . The reliability results of REMO original form

\begin{tabular}{llllll}
\hline Scale & Sub-Scales & Number of Items & $\alpha$ & Split- half & Test re-test \\
\hline \multirow{3}{*}{ P-REMO } & Peers as positive motivators & 9 & .80 & .78 & .70 \\
& Peers as negative motivators & 6 & .73 & .75 & .71 \\
& Individual learning behaviour & 6 & .80 & .79 & .78 \\
\multirow{2}{*}{ T-REMO } & Teachers as positive motivators & 6 & .78 & .81 & .75 \\
& Teachers as negative motivators & 10 & .82 & .81 & .81 \\
\hline
\end{tabular}

Source. Raufelder et al. (2013).

According to the results, the original REMO scale was found to be reliable. Furthermore, various validity tests (see Raufelder et al., 2013) indicate that the scale is also valid.

\subsubsection{Procedure}

The adaptation procedure of REMO to Turkish language involves multiple stages described by Hambleton and Patsula (1999). Firstly, the scale was translated into Turkish by two different language specialists and researchers. The translated version was back-translated into English by four academicians specialized in English language. This version was then compared to the original version of the scale by the researchers. It was also reviewed by five people specialized in teaching Turkish grammar. After making necessary revisions to the scale according to the feedback, the first version of the Turkish adaptation was finalized.

For the evaluation of the linguistic equivalence for the Turkish scale, both the original and the adapted forms were administered to the students at one-week intervals, and expert opinion was sought. For this purpose, a form was created and sent to two English language experts and two assessment and evaluation experts. They reviewed the scale items to see whether equivalence was achieved in terms of semantics, experiments, conception and idioms.

Within the framework of the data gathered from the pilot study, some words and phrases were revised to achieve content integrity within the scale. Some of the revisions were necessary because the students in the age group of 11-12 years were not familiar with the some of the phrases. 


\subsubsection{Data Analysis}

In order to assess the linguistic equivalence of the adapted form of the scale, Spearman's Rank Correlation Coefficient (SRCC) was used. SRCC was chosen since the normality assumptions was not establied and the number of the university students was lower than $30(n=20)$. To determine whether consistency between linguistic and field experts was established, the inter-rater reliability (Grayson \& Rust, 2001) was calculated.

For the first version of the Turkish form, an Explanatory Factor Analysis (EFA) was carried out for P-REMO and T-REMO, separately as in the original scale. Before performing EFA, Kaiser-Mayer-Olkin (KMO) coefficient was calculated and Barlett Test was performed. The results of these tests showed that the responses given to items in this scale could be factorized.

Prior to the data analysis, in order to ensure that the assumptions had not been violated, they were checked and it was found that all the assumptions (missing data, outliers, normality, multicollinearity, etc.) were established. The analyses were tested using SPSS, Mplus and LISREL software.

\subsection{Results}

SRCCs obtained from the original and Turkish versions of the REMO scale varied between .62 and .92, indicating that the correlations ranged from moderate to high (Hinkle, Wiersma, \& Jurs, 2003). Concerning the opinions of the linguistic experts about linguistic equivalence, the consistency between them was found to be $96 \%$. Within the framework of these results, it can be stated that linguistic equivalence was achieved for the adapted version. The results of EFA conducted for the pilot study are given in Table 2 .

Table 2. Factor loadings of P-REMO and T-REMO in pilot study

\begin{tabular}{|c|c|c|c|c|c|c|c|c|}
\hline \multicolumn{4}{|c|}{ Item } & \multicolumn{5}{|c|}{ Item } \\
\hline & Number & F1 & F2 & F3 & & Number & F1 & F2 \\
\hline \multicolumn{4}{|c|}{ Factor 1: Peers as Positive Motivators } & & \multicolumn{4}{|c|}{ Factor 1: Teachers as Positive Motivators } \\
\hline & 35 & .71 & .03 & .01 & & 20 & .72 & -.01 \\
\hline & 21 & .63 & .01 & -.12 & & 10 & .65 & -.15 \\
\hline & 26 & .63 & .19 & -.01 & & 33 & .64 & -.07 \\
\hline & 31 & .57 & .18 & -.37 & & 36 & .64 & -.02 \\
\hline & 16 & .55 & .22 & -.04 & & 25 & .62 & .09 \\
\hline & 11 & .50 & -.29 & .11 & & 37 & .59 & -.07 \\
\hline & 32 & .48 & -.06 & .17 & & 30 & .59 & -.10 \\
\hline & 1 & .43 & -.13 & -.17 & & 15 & .56 & .07 \\
\hline & 8 & -.41 & .40 & -.28 & & 5 & .53 & .16 \\
\hline & 6 & .31 & .01 & -.29 & & 34 & .42 & .10 \\
\hline \multicolumn{5}{|c|}{ Factor 2: Peers as Negative Motivators } & \multicolumn{4}{|c|}{ Factor 2: Teachers as Negative Motivators } \\
\hline & 2 & -.03 & .04 & .63 & & 14 & .03 & .74 \\
\hline & 12 & .11 & -.05 & .60 & & 19 & -.09 & .72 \\
\hline & 22 & -.21 & .22 & .55 & & 24 & -.10 & .68 \\
\hline & 17 & -.00 & -.12 & .55 & & 9 & -.07 & .67 \\
\hline & 27 & -.16 & -.02 & .42 & & 29 & .06 & .66 \\
\hline & 7 & .09 & .10 & .32 & & & & \\
\hline \multicolumn{9}{|c|}{ Factor 3: Individual Learning } \\
\hline & 23 & .15 & .74 & .04 & & & & \\
\hline & 3 & .06 & .73 & .00 & & & & \\
\hline & 28 & .08 & .72 & .05 & & & & \\
\hline & 18 & -.36 & .58 & -.09 & & & & \\
\hline & 13 & .03 & .47 & .08 & & & & \\
\hline $\begin{array}{l}\text { Explained } \\
\text { Variance \% }\end{array}$ & Total: 37.13 & 15.17 & 12.59 & 9.37 & $\begin{array}{l}\text { Explained } \\
\text { Variance \% }\end{array}$ & Total: 40.44 & 26.09 & 14.35 \\
\hline
\end{tabular}

For P-REMO, the ranges of the factor loadings of the items were .31-.71, .47-.74 and .32-.63 for Factors 1, 2, and 3 , respectively. Together, all the three factors explained $37.13 \%$ of the total variance. In addition, when the factor loadings of the items were further examined, it was seen that item 8 had a high loading on more than one factor and that the difference between the factor loadings was less than .10. For this reason, this item was 
considered to be an overlapping item (Tabachnick \& Fidell, 2007), and was adjusted to make it more clear to ensure that it would be understood in the same way by all individuals in the study group. In addition, the highest loading of item 6 was found to be below .32, which made it inadequate to explain its relevant factor (Tabachnick $\&$ Fidell, 2007); therefore, this item was also revised.

As seen in Table 2, for T-REMO, the factor loadings of the items under Factor 1 varied between .42 and .72 and those under Factor 2 ranged from .66 to .74. Together, Factors 1 and 2 explained $40.44 \%$ of the total variance. At the same time, it is clear from Table 2 that none of the items overlapped or failed to achieve the acceptable level for factor loadings. However, it was observed that in T-REMO, item 5 had high loadings on different factors compared to those in the original scale. Therefore, the item was rephrased.

\section{Study 2}

\subsection{Method}

\subsubsection{Participants and Procedure}

The participants of Study 2 consisted of Turkish students enrolled in the 6th to 9th grades during the 2014-2015 academic years. Specifically, 496 students $\left(\mathrm{M}_{\mathrm{age}}=14.30, \mathrm{sd}=1.24\right.$, range=11-17; 194 girls, 302 boys $)$ took part in the testing of the conformity of the factor structure of REMO, and 528 students $\left(\mathrm{M}_{\mathrm{age}}=14.10, \mathrm{sd}=1.26\right.$, range $=11-17 ; 225$ girls, 303 boys) were recruited for validity and reliability analyses. In order to ensure the representativeness of the high, medium, and low socio-economic levels, schools were selected from three provinces in Turkey representing different socio-economic levels according to the indicators of socio-economic development. As a result, six public schools (45 randomly selected classes) participated in the survey, of which three were high schools and three were middle schools.

Prior to the data analysis, in order to ensure that the assumptions had not been violated, they were checked and it was found that all the assumptions (missing data, outliers, normality, multicollinearity, etc.) were established. The confirmatory procedures for the original REMO were based on parcels to build from the factor items determined by the factor analysis (Raufelder et al., 2013). However, in this study, it was preferred to use single items for two main reasons; (i) the use of parcels in structural or confirmatory models is considered a questionable practice in the literature (Little, Cunningham, Shahar, \& Widaman, 2002) and (ii) the relationships between latent variables were not the focus of this study.

To determine the accuracy of the structure of the adapted scale in relation to the original scale, a Confirmatory Factor Analysis (CFA) was performed. The following were used as fit indices; chi-square $\left(x^{2}\right)$, chi-square/degrees of freedom $\left(x^{2} / \mathrm{df}\right)$, Root-Mean-Square Error of Approximation (RMSEA), Standardized Root Mean square Residual (SRMR), Comparative Fit Index (CFI), Non-Normed Fit Index (NNFI), Goodness-of-Fit Index (GFI), and Adjusted GFI (AGFI). Furthermore, an EFA was carried out to gather evidence for the validity of the Turkish REMO. Before performing EFA, the KMO coefficient was calculated and Barlett Test was conducted. The results of these tests showed that the responses given to the items in the adapted version of the scale could be factorized. The reliability of the Turkish version of REMO was calculated using the coefficients of split-half reliability, Hancock's H (Hancock \& Mueller, 2001), and Cronbach's alpha.

\subsection{Results}

\subsubsection{Verification of REMO in the Turkish Culture}

CFA was carried out to examine the extent to which the data obtained from the adapted P-REMO conformed to the original structure with three sub-factors, several goodness-of-fitness indices were obtained as follows: $x^{2}=640.10(\mathrm{~N}=496, \mathrm{df}=186, \mathrm{p}<.01), x^{2} / \mathrm{df}=3.44, \mathrm{RMSEA}=.07, \mathrm{SRMR}=.08, \mathrm{CFI}=.83, \mathrm{NNFI}=.81, \mathrm{GFI}=.90$ and $\mathrm{AGFI}=.80$. According to the findings, the NNFI value indicated a poor fit; $x^{2} / \mathrm{df}$, CFI and AGFI values demonstrated an acceptable fit; and RMSEA, SRMR and GFI values showed a good fit (Hu \& Bentler, 1999; Steiger, 2007). An acceptable fit between the data and the model was achieved. All the standardized factor loadings were higher than .23 and the t-values of the items were significant $(p<.05)$. The item loadings regarding sub-factor peers as positive and negative motivators ranged from .25 to .56 and .26 to .60 , respectively, and those concerning sub-factor individual learning varied between .23 and .63. In brief, the results of CFA for P-REMO showed that the original structure was preserved in the adapted scale.

CFA was also performed to examine the conformity of the data gathered from T-REMO to the original REMO with two sub-factors, and to examine the accuracy of the structure of the adapted version in relation to the original form. Regarding goodness-of-fit indices, the following values were obtained: $x^{2}=275.85(\mathrm{~N}=496$, $\mathrm{df}=103, \mathrm{p}<.01), x^{2} / \mathrm{df}=2.68, \mathrm{RMSEA}=.06, \mathrm{SRMR}=.07, \mathrm{CFI}=.95, \mathrm{NNFI}=.94, \mathrm{GFI}=.93$, and $\mathrm{AGFI}=.91$. Based on 
these results, RMSEA, SRMR, NNFI, AGFI, and GFI indicated a good fit, and the $x^{2} / \mathrm{df}$ and CFI values showed a perfect fit (Kline, 2005; Hu \& Bentler, 1999; Schumacker \& Lomax, 1996). Overall, there was a good fit between the data and the model. According to the CFA model of T-REMO, all the standardized factor loadings were higher than .45 and the $\mathrm{t}$ values of the items were significant $(\mathrm{p}<.05)$. The item loadings regarding sub-factor teachers as positive and negative motivators ranged from .48 to .63 , and from .45 to .63 , respectively. In brief, the results of CFA for T-REMO supported the claim that the structure of the original REMO was maintained in the adapted scale.

Construct validity of the Turkish version of REMO. EFA was carried out to gather evidence for the construct validity of P-REMO and T-REMO. The results showed that the number of principle factors was three for PREMO and two for T-REMO. When determining the number of factors with EFA, the factor loading values of the scale items were also checked. Factor loadings of P-REMO and T-REMO in Study 2 were given in Table 3.

Table 3. Factor loadings of P-REMO and T-REMO in Study 2

\begin{tabular}{|c|c|c|c|c|c|c|c|c|c|c|}
\hline & $\begin{array}{l}\text { Item } \\
\text { Number }\end{array}$ & $\begin{array}{l}\text { Original } \\
\text { F1 }\end{array}$ & $\mathrm{F} 1$ & $\mathrm{~F} 2$ & F3 & & $\begin{array}{c}\text { Item } \\
\text { Number }\end{array}$ & $\begin{array}{l}\text { Original } \\
\text { F1 }\end{array}$ & $\mathrm{F} 1$ & $\mathrm{~F} 2$ \\
\hline \multirow{11}{*}{$\begin{array}{l}\text { Factor 1: Peers } \\
\text { Positive Motivators }\end{array}$} & 26 & .52 & .67 & -.02 & .02 & \multirow{10}{*}{$\begin{array}{l}\text { Factor 1: Teachers as } \\
\text { Positive Motivators }\end{array}$} & 33 & .75 & .75 & -.08 \\
\hline & 1 & .67 & .59 & -.04 & .02 & & 25 & .62 & .69 & -.03 \\
\hline & 35 & .64 & .56 & -.10 & .05 & & 30 & .61 & .68 & -.08 \\
\hline & 21 & .64 & .55 & -.21 & .13 & & 37 & .67 & .66 & -.08 \\
\hline & 31 & .65 & .55 & -.31 & .15 & & 10 & .62 & .63 & -.14 \\
\hline & 16 & .72 & .48 & .03 & .05 & & 5 & .55 & .63 & .07 \\
\hline & 11 & .56 & .48 & .07 & -.21 & & 20 & .61 & .63 & -.04 \\
\hline & 32 & .60 & .44 & .11 & -.14 & & 36 & .56 & .61 & .12 \\
\hline & \multirow{2}{*}{6} & \multirow[t]{2}{*}{.58} & \multirow[t]{2}{*}{.42} & \multirow[t]{2}{*}{-.32} & \multirow[t]{2}{*}{-.02} & & 15 & .56 & .59 & .21 \\
\hline & & & & & & & 34 & .61 & .54 & .10 \\
\hline & $\begin{array}{c}\text { Item } \\
\text { Number }\end{array}$ & $\begin{array}{l}\text { Original } \\
\text { F2 }\end{array}$ & $\mathrm{F} 1$ & $\mathrm{~F} 2$ & F3 & \multirow{7}{*}{$\begin{array}{l}\text { Factor 2: Teachers as } \\
\text { Negative Motivators }\end{array}$} & $\begin{array}{c}\text { Item } \\
\text { Number }\end{array}$ & $\begin{array}{l}\text { Original } \\
\text { F2 }\end{array}$ & F1 & $\mathrm{F} 2$ \\
\hline \multirow{7}{*}{$\begin{array}{l}\text { Factor 2: Peers as } \\
\text { Negative Motivators }\end{array}$} & 17 & .69 & -.11 & .73 & -.06 & & 14 & .74 & -.02 & .75 \\
\hline & 27 & .67 & -.05 & .69 & -.04 & & 9 & .71 & -.01 & .69 \\
\hline & 12 & .66 & -.08 & .64 & -.08 & & 24 & .71 & -.12 & .68 \\
\hline & 22 & .70 & .08 & .60 & -.01 & & 19 & .65 & -.06 & .64 \\
\hline & 2 & .66 & -.11 & .47 & -.14 & & 29 & .68 & .04 & .61 \\
\hline & 7 & .69 & .02 & .41 & .18 & & 4 & .64 & .20 & .54 \\
\hline & $\begin{array}{c}\text { Item } \\
\text { Number }\end{array}$ & $\begin{array}{l}\text { Original } \\
\text { F3 }\end{array}$ & F1 & F2 & F3 & & & & & \\
\hline \multirow{6}{*}{$\begin{array}{l}\text { Factor 3: Individual } \\
\text { Learning }\end{array}$} & 3 & .66 & -.01 & -.09 & .69 & & & & & \\
\hline & 23 & .67 & .04 & -.14 & .66 & & & & & \\
\hline & 28 & .84 & .23 & .07 & .64 & & & & & \\
\hline & 18 & .71 & -.33 & -.01 & .61 & & & & & \\
\hline & 13 & .66 & .08 & .04 & .52 & & & & & \\
\hline & 8 & .64 & -.38 & -.04 & .48 & & & & & \\
\hline Explained Variance \% & $\begin{array}{l}\text { Total: } \\
37.03\end{array}$ & - & 15.78 & 12.25 & 9.00 & Explained Variance \% & $\begin{array}{l}\text { Total: } \\
42.93\end{array}$ & - & 26.57 & 16.36 \\
\hline
\end{tabular}

The results as given in Table 3 for P-REMO show that the factor loading values of the items under Factors 1, 2, and 3 ranged from .42 to $.67, .41$ to .73 , and .48 to .69 , respectively. The items were further examined to determine whether they loaded on more than one factor and whether they achieved the acceptable level of factor loading values. It is found that none of the items overlapped or failed to meet the acceptance level of factor loading. The explained factor variances of the Turkish version of P-REMO were found to be $15.78 \%, 12.25 \%$, and $9.00 \%$ for Factors 1, 2, and 3, respectively. Together, the three factors explained $37.03 \%$ of the total variance similar to of the results obtained from the original version of P-REMO $(16.18 \%, 10.96 \%$, and $10.22 \%$, respectively see: Raufelder et al., 2013). 
As shown in Table 3, for T-REMO, the factor loading values of the items under Factor 1 varied between .54 and .75 , and those under Factor 2 ranged from .54 to .75. Furthermore, it was found that none of the items loaded on more than one factor and all the items had factor loading values that were at an acceptance level. The explained factor variances of the Turkish version of T-REMO were calculated as $26.57 \%$ and $16.36 \%$ for Factors 1 and 2, respectively. Together, the two factors explained $42.93 \%$ of the total variance similar to the case in the original T-REMO (26.33\% and $14.67 \%$, respectively, see: Raufelder et al., 2013).

\subsubsection{Reliability of the Turkish REMO}

In this process of the reliability analysis, the coefficients of split-half reliability, Cronbach's alpha, and Hancock's H were determined (Table 4).

Table 4. Reliability coefficient regarding REMO

\begin{tabular}{llcccc}
\hline Scale & Sub-Scales & Item Number & Split-half & $\alpha$ & $H$ \\
\hline \multirow{3}{*}{ P-REMO } & Peers as Positive Motivators & 9 & .67 & .70 & .69 \\
& Peers as Negative Motivators & 6 & .64 & .65 & .71 \\
& Individual Learning Behaviour & 6 & .62 & .67 & .68 \\
\hline \multirow{2}{*}{ T-REMO } & Teachers as Positive Motivators & 6 & .70 & .73 & .72 \\
& Teachers as Negative Motivators & 10 & .81 & .84 & .83 \\
\hline
\end{tabular}

As shown in Table 4, the coefficient $\mathrm{H}$ values of the subscales were adequately high with the exception of the individual learning behavior subscale $(H=.68)$. However, this value was very close to the acceptable limit of .70 . The coefficient $H$ values of the remaining subscales ranged from .69 (peers as positive motivators) to .83 (teachers as negative motivators). Moreover, other reliability coefficients were found to be higher than .62 for P-REMO and higher than .70 for T-REMO. According to Nunnally and Bernstein (1994), if the reliability coefficient is between .60 and .80 , this indicates a fair or marginal-level of reliability. Therefore, the T-REMO and P-REMO sub-scales of the adapted REMO were considered to have moderate reliability.

\section{Study 3}

\subsection{Method}

The same participants of Study 2 were included in Study 3. The total number of students was 1024 (419 girls, 605 boys) with their age ranging from 11 to $17\left(\mathrm{M}_{\mathrm{age}}=14.20, \mathrm{sd}=1.25\right)$. To examine whether measurement invariance was achieved for gender groups, a Multi-Group Confirmatory Factor Analysis (MGCFA) was carried out. Furthermore, a t-test was performed to analyze the difference between the scores of girls and boys.

\subsection{Results}

The results of MGCFA are given in Table 5 .

Table 5. Fit statistics for REMO across sex

\begin{tabular}{|c|c|c|c|c|c|c|c|c|c|}
\hline \multicolumn{10}{|l|}{ P-REMO } \\
\hline Invariance & $x^{2}$ & $\mathrm{df}$ & $x^{2} / \mathrm{sd}$ & RMSEA & CFI & SRMR & $\triangle$ RMSEA & $\Delta \mathrm{CFI}$ & $\Delta$ SRMR \\
\hline Girls & 447.15 & 186 & 2.40 & .06 & .81 & .07 & - & - & - \\
\hline Boys & 594.73 & 186 & 3.20 & .06 & .74 & .07 & - & - & - \\
\hline Configural & 1041.88 & 372 & 2.80 & .06 & .77 & .07 & - & - & - \\
\hline Metric & 1076.76 & 390 & 2.76 & .06 & .77 & .07 & .01 & .02 & .01 \\
\hline Partial Metric & 1074.83 & 389 & 2.76 & .06 & .77 & .07 & .01 & .02 & .01 \\
\hline Scalar & 1270.35 & 411 & 3.09 & .06 & .71 & .08 & .01 & .08 & .02 \\
\hline \multicolumn{10}{|l|}{ T-REMO } \\
\hline Girls & 318.39 & 103 & 3.09 & .07 & .88 & .07 & - & - & - \\
\hline Boys & 287.79 & 103 & 2.79 & .05 & .90 & .05 & - & - & - \\
\hline Configural & 606.18 & 206 & 2.94 & .06 & .89 & .06 & - & - & - \\
\hline Metric & 850.94 & 220 & 3.87 & .11 & .57 & .13 & .04 & .32 & .07 \\
\hline Partial Metric & 626.02 & 219 & 2.86 & .06 & .89 & .06 & .01 & .01 & .01 \\
\hline Scalar & 732.71 & 236 & 3.10 & .06 & .86 & .08 & .01 & .05 & .02 \\
\hline Partial Scalar & 709.30 & 220 & 3.22 & .07 & .86 & .08 & .01 & .02 & .01 \\
\hline
\end{tabular}


For P-REMO, fit indices obtained from CFA conducted separately on girls and boys showed an acceptable fit of the model to the data for both groups of participants $\left(x^{2}=447.15, \mathrm{df}=186, \mathrm{p}<.01, \mathrm{CFI}=.80, \mathrm{SRMR}=.06\right.$, RMSEA $=.06$ for girls and $x^{2}=594.73, \mathrm{df}=186, \mathrm{p}<.01, \mathrm{CFI}=.74, \mathrm{SRMR}=.07, \mathrm{RMSEA}=.06$ for boys). The invariance analysis showed that configural invariance $\left(x^{2}=1041.88, \mathrm{df}=372, \mathrm{p}<.01, x^{2} / \mathrm{df}=2.80, \mathrm{CFI}=.77\right.$, $\mathrm{SRMR}=.07, \mathrm{RMSEA}=.06)$ was achieved but metric invariance $\left(x^{2}=1076.76, \mathrm{df}=390, \mathrm{p}<.01, x^{2} / \mathrm{df}=2.76\right.$, $\mathrm{CFI}=.77, \mathrm{SRMR}=.07, \mathrm{RMSEA}=.06, \Delta \mathrm{CFI}=.02)$ was not established. Therefore, partial metric invariance tests were conducted by freeing the factor loadings of items 6,12, and 18 in P-REMO that were not found to be metrically invariant across groups. As a result, partial metric invariance was not achieved in the model since the value of modification index $\Delta$ CFI was above $.01\left(x^{2}=1074.83, \mathrm{df}=389, \mathrm{p}<.01, x^{2} / \mathrm{df}=2.76, \mathrm{CFI}=.77, \mathrm{SRMR}=.07\right.$, RMSEA $=.06, \Delta \mathrm{CFI}=.02$ ).

As shown in Table 5, according to the results of CFA, the fit indices for T-REMO showed an acceptable fit of the model to the data obtained from girls $\left(x^{2}=318.386, \mathrm{df}=103, \mathrm{p}<.01, \mathrm{CFI}=.88, \mathrm{SRMR}=.07, \mathrm{RMSEA}=.07\right)$, and boys $\left(x^{2}=287.794, \mathrm{df}=103, \mathrm{p}<.01, \mathrm{CFI}=.90, \mathrm{SRMR}=.05\right.$, RMSEA $\left.=.05\right)$. The invariance analysis revealed that configural invariance $\left(x^{2}=606.180, \mathrm{df}=206, \mathrm{p}<.01, x^{2} / \mathrm{df}=2.94, \mathrm{CFI}=.89, \mathrm{SRMR}=.06\right.$, RMSEA $\left.=.06\right)$ had been established but metric invariance $\left(x^{2}=850.94, \mathrm{df}=220, \mathrm{p}<.01, x^{2} / \mathrm{df}=3.87, \mathrm{CFI}=.57\right.$, SRMR $=.13$, RMSEA $=.10$, $\Delta \mathrm{CFI}=.32$ ) had not been achieved. Therefore, partial metric invariance tests were conducted by freeing the factor loadings of item 5 in T-REMO that were metrically invariant across groups. As a result, partial metric invariance was achieved in the model $\left(x^{2}=626.02, \mathrm{df}=219, \mathrm{p}<.01, x^{2} / \mathrm{df}=2.86, \mathrm{CFI}=.89\right.$, SRMR $=.07$, RMSEA $=.06$, $\Delta \mathrm{CFI}=.01)$. However, scalar invariance $\left(x^{2}=732.71, \mathrm{df}=236, \mathrm{p}<.01, x^{2} / \mathrm{df}=3.10, \mathrm{CFI}=.86, \mathrm{SRMR}=.08\right.$, RMSEA =.06) was not established. Therefore, partial scalar invariance tests were performed by freeing the intercept of item 5 in T-REMO. Results indicated that partial scalar invariance $\left(x^{2}=709.30, \mathrm{df}=220, \mathrm{p}<.01\right.$, $x^{2} / \mathrm{df}=3.22, \mathrm{CFI}=.86, \mathrm{SRMR}=.08, \mathrm{RMSEA}=.06$ ) was not established. When the overall results are evaluated while configural invariance models $(.77 \leq \mathrm{CFI} \leq 89 ; .05 \leq \mathrm{RMSEA} \leq .06)$ were maintained in all subscales, metric invariance models were not maintained in any of the subscales $(.90 \leq \mathrm{CFI} \leq .96 ; .06 \leq \mathrm{RMSEA} \leq .09)$.

When the results regarding measurement invariance of P-REMO and T-REMO were examined, of all the modification indices, CFI was found to be lower than the acceptable cut-off limit. Therefore, in this study, the values of several modification indices were taken into consideration together. The difference between the scores of girls and boys was determined using a t-test (Table 6).

Table 6. Means, standard deviations, and coefficient $\mathrm{t}$ for girls and boys

\begin{tabular}{|c|c|c|c|c|c|c|}
\hline \multirow[b]{2}{*}{ Subscales } & & \multicolumn{2}{|c|}{ Girls } & \multicolumn{2}{|c|}{ Boys } & \multirow{2}{*}{$t$} \\
\hline & & M & $\mathrm{SD}$ & $\mathrm{M}$ & SD & \\
\hline \multirow[t]{3}{*}{ P-REMO } & PPM & 26.94 & 4.29 & 25.56 & 4.44 & $4.92 *$ \\
\hline & PNM & 8.98 & 2.80 & 10.63 & 3.19 & $-8.67 *$ \\
\hline & ILB & 15.73 & 3.83 & 15.39 & 3.51 & 1.45 \\
\hline \multirow[t]{2}{*}{ T-REMO } & TPM & 21.54 & 2.59 & 20.19 & 3.08 & $7.54 *$ \\
\hline & TNM & 22.33 & 6.72 & 21.42 & 5.92 & $2.22 *$ \\
\hline
\end{tabular}

${ }^{*} p<.05$.

As shown in Table 6, the results indicated significant differences between boys and girls in terms of their PPM, TPM and TNM subscale scores. The girls had significantly higher mean scores in three subscales while boys had significantly higher mean scores in the PNM subscale. Regarding individual learning, results did not show any significant difference for individual learning.

\section{General Discussion}

The main aim of this study was to adapt the REMO scale to the Turkish culture. To achieve this aim, three separate studies were conducted. Specifically, In Study 1, linguistic equivalence was established and the factor structure was determined. Study 2 determined whether the original structure was maintained in the adapted version, and the levels of validity and reliability of the Turkish REMO was examined. In Study 3, measurement invariance across sex was tested, and the differences between the scores of the two groups were analyzed.

According to the results of Study 1, the linguistic equivalence of the scale was achieved. However, several items needed to be revised. Study 2 showed that the structure of the original REMO (P-REMO with three sub-factors and T-REMO with two sub-factors) was preserved in the adapted version. In addition, evidence was provided for the validity, reliability of the Turkish version of the scale. In Study 3, configural invariance across sex was 
maintained in all subscales; however, metric invariance across sex models was not achieved in any of the subscales. Additionally, the roles of teachers and peers as motivators were different for girls and boys whereas the role of individual learning did not show any difference between the two groups.

This study suggests that the factor structure of the Turkish REMO is similar to the original scale despite the cultural differences between the Turkish and German students. Turkish students come from a collectivistic culture (Kagitcibasi, 1996) while German students from an individualistic culture (Trumbull \& Rothstein-Fisch, 2011) with different characteristics. In the near future, this study can be extended to explore potential differences between German and Turkish adolescents in their socio-motivational relations with their peers and teachers, which would allow comparing the cultural differences between the two countries.

When the findings obtained from Studies 1 and 2 are evaluated, the psychometric properties of the Turkish REMO indicate that it is a valid and reliable scale for measuring the relationships of students with their peers and teachers as motivators. Additionally, the total explained variance and reliability coefficients of T-REMO were found to be higher than those of P-REMO although the number of items included in the former was less compared to the latter. One of the possible explanations for this result may be that students consider their relationships with their teachers as more important than peer relationships as suggested by Trumbull and Rothstein-Fisch (2011). Moreover, several modification indices related to the factor structure of the Turkish REMO did not show a good fit of the model. The lower values of modification indices compared to the original REMO may be attributed to the variations in the measured structure according to different cultures. During the adaptation process, some problematic words or phrases were encountered and they were revised. Furthermore, due to the potential differences between different cultures regarding motivational dependency on teachers and peers (e.g., Chiu \& Chow, 2010; Hesse, 2004), it may be difficult to establish a model with the same factor structure and loadings for Turkish students as members of a collectivistic culture and for German students as members of an individualistic culture.

In Study 3, based on the results of measurement invariance for the adapted P-REMO, the constructs were found to be somewhat different for boys and girls. The results regarding metric invariance revealed that several items (i.e., item 6 "My friends and I motivate each other to make an effort at school", item 12 "When my friends find school boring, I also tend to find school tiresome", and item 26 "I will study harder for an exam when my friends tell me that they are also working hard") were found to have higher factor loadings on their corresponding factors for the group of girls. These items were better indicators of peers influence on the motivation of girls. These findings are supported by the study of Goodenow and Grady (1993), who indicated that girls are more susceptible to peer influence. Considering the characteristics of their friendship, girls are more likely to establish close and dependent relationships with their peers (Henrich, Blatt, Kuperminc, Zohar, \& Leadbeater, 2001). Therefore, in order not to be alone, they tend to care more about what their friends think. This may also result from the culture of obedience in Turkey (Goka, 2006). Goka explains that in this culture, especially the level of girls' autonomy is lower than that of boys. In educational settings, this may cause girls to be more dependent in their relations with peers and teachers. However, in the presents study, girls and boys did not differ in individual learning behavior. This may be related to the social culture in Turkey. Specifically, in the collectivist countries such as Turkey, a high value is given to the interdependency of its members (Kagitcibasi, 1996). In the educational context, students from collectivistic cultures exhibit more socio-motivational dependence (Chiu \& Chow, 2010). On the other hand, in the individualistic countries such as Germany, socio-motivational dependence is not a dominant factor for students. Rather, these students are seen as independent and self-contained individuals (Hesse, 2004).

Multi-group invariance testing across sex revealed that the factor structure of the adapted T-REMO was a satisfactory representation of teachers' role as a motivator for both boys and girls. That is, configural invariance was obtained across both gender groups. On the other hand, the results of metric invariance indicated that the factor loadings of the T-REMO items showed inconsistency across sex. That is, the contribution of the items to determining the role of teachers as motivators differed for boys and girls. Therefore, when the factor loadings of the items were examined, it was concluded that item 4 (i.e., "when a teacher likes me, I make more effort in the subject") had a higher factor loading on its corresponding factor for the group of girls. The findings of the study are consistent with earlier research on adolescent perceptions of caring teachers (Sullivan, Ricco, \& Reynolds, 2008). The authors revealed that the girls were more likely to receive care from their teacher, which in turn positively affected their academic motivation. That is, girls' perception of their closeness determines the level of their motivation. On the other hand, boys tended to have conflictual relations with their teachers and they are also emotionally less attached to their teachers. This situation causes boys to have a low level of motivation and attendance to school (Huan, Quek, Yeo, Ang, \& Chong, 2012). The results of the t-test analysis also supported 
these findings. More precisely, girls had statistically significantly higher mean scores for this subscale. Similar to the previous results on T-REMO, these results also show that girls are more likely to be influenced by their teachers.

As a result, the adapted scale provided information about the relations of students with their peers and teachers, and how these relations motivate them. Therefore, it is considered to be relevant for education stakeholders. School psychologists can utilize this scale to gain insight into the roles of peers and teachers in the motivational process of students. This way, they can detect motivational problems in school, which will help improve the characteristics of the class environment and academic achievement.

This study has certain limitations. Firstly, the participants were selected only from three provinces, which may affect the generalizability of the findings. Moreover, in this study, criterion validity could not be performed with other measurement tools. Therefore, there is a need for further studies, in which other assessment instruments available in the literature will be used to assess students' motivation. In this study, P-REMO and T-REMO scores differed between boys and girls. In this regard, studies focusing on differential item functioning should be carried out with the data gathered from the adapted REMO in terms of different variables (e.g., sex and class).

In this study, multi-level model analyses could not be performed since the research was not based on a design with a multi-level basis; thus, some of the assumptions of the model were not met. Future studies can be conducted using multi-level models. Moreover, it is recommended that studies focusing on differences sex and utilizing the Turkish REMO should establish measurement invariance in order to make valid inferences.

\section{Acknowledgments}

The necessary permission for adaptation of REMO was granted by Raufelder et al. (2013) for this study.

\section{References}

Armitage, D., Marschke, M., \& Plummer, R. (2008). Adaptive co-management and the paradox of learning. Global Environmental Change, 18(1), 86-98. https://doi.org/10.1016/j.gloenvcha.2007.07.002

Aydın, A. (2008). Ĕgitim psikolojisi: Gelişim, öğrenme, öğretim [Educational psychology: Development, learning and instruction]. Ankara: Pegem Yayıncilık.

Becker, B. E., \& Luthar, S. S. (2002). Social-emotional factors affecting achievement outcomes among disadvantaged students: Closing the achievement gap. Educationalist Psychologist, 37(4), 197-214. https://doi.org/10.1207/S15326985EP3704_1

Bowlby, J. (1969). Attachment and loss. Attachment vol. 1. New York, NY: Basic Books.

Bretherton, I. (1987). New perspectives on attachment relations: Security, communication and internal working models. In J. Osofsky (Ed.), Handbook of infant development (pp. 1061-1100). New York, NY: Wiley.

Chiu, M. M., \& Chow, B. W. Y. (2010). Culture, motivation, and reading achievement: High school students in 41 countries. Learning and Individual Differences, 20, 579-592. https://doi.org/10.1016/j.lindif.2010.03.007

Csizér, K., \& Dörnyei, Z. (2005). The internal structure of language learning motivation and its relationship with language choice and learning effort. The Modern Language Journal, 89(1), 19-36. https://doi.org/10.1111/j.0026-7902.2005.00263.x

Deci, E. L., \& Ryan, R. M. (1985). Intrinsic motivation and self-determination in human behavior. New York, NY: Plenum. https://doi.org/10.1007/978-1-4899-2271-7

Deci, E. L., \& Ryan, R. M. (2000). Handbook of Self-determination Research. Rochester, NY: University of Rochester Press.

Deci, E. L., \& Ryan, R. M. (2008). Facilitating optimal motivation and psychological well-being across life's domains. Canadian Psychology, 49(1), 14-23. https://doi.org/10.1037/0708-5591.49.1.14

Dunn, R., \& Honigsfeld, A. (2013). Learning Styles: What we know and what we need. The Educational Forum, 77(2), 225-232. https://doi.org/10.1080/00131725.2013.765328

Elliot, A. J. (1997). Integrating the "classic" and the "contemporary" approaches to achievement motivation: A hierarchical model of approach and avoidance achievement motivation. In M. L. Maehr, \& P. R. Pintrich (Ed.), Advances in motivation and achievement (pp. 143-179). Greenwich, CT: JAP Press.

Engin, M., \& McKeown, K. (2012). Cultural influences on motivational issues in students and their goals for studying at university. Learning and Teaching in Higher Education: Gulf Perspectives, 9(1), 1-15. 
Fan, W., \& Williams, C. M. (2010). The effects of parental involvement on students' academic self-efficacy, engagement and intrinsic motivation. Educational Psychology, 30(1), 53-74. https://doi.org/10.1080/01443410903353302

Goka, E. (2006). Türk Grup Davranışı [Turkish group behaviour]. Ankara: Aşina Kitaplar.

Goodenow, C., \& Grady, K. E. (1993). The relationship of school belonging and friends' values to academic motivation among urban adolescent students. Journal of Experimental Education, 62(1), 60-71. https://doi.org/10.1080/00220973.1993.9943831

Grayson, K., \& Rust, R. T. (2001). Interrater reliability. Journal of Consumer Psychology, 10(1\&2), 71-73. https://doi.org/10.1207/S15327663JCP1001\&2_06

Hambleton, R. K., \& Patsula, L. (1999). Increasing the validity of adapted tests: Myths to be avoided and guidelines for improving test adaptation practices. Journal of Applied Testing Technology, 1(1), 1-13. Retrieved from http://www.jattjournal.com/index.php/atp/article/view/48345/39215

Hancock, G. R., \& Mueller, R. O. (2001). Rethinking construct reliability within latent variable systems. In R. Cudeck, S. Du Toit, \& D. Söbom (Eds.), Structural equation modeling: Present and future (pp. 195-216). Lincolnwood, IL: Scientific Software International.

Henrich, C. C., Blatt, S. J., Kuperminc, G. P., Zohar, A., \& Leadbeater, B. J. (2001). Levels of interpersonal concerns and social functioning in early adolescent boys and girls. Journal of Personality Assessment, 76(1), 48-67. https://doi.org/10.1207/S15327752JPA7601_3

Hesse, H. G. (2004). Values and attitudes and their influence on education. In H. Döbert, E. Klieme, \& W. Sroka (Eds.), Conditions of school performance in seven countries. A quest for understanding the international variation of PISA results (pp. 302-304). Münster, Germany: Waxmann.

Hinkle, D. E., Wiersma, W., \& Jurs, S. G. (2003). Applied statistics for the behavioral sciences. Boston, MA: Houghton Mifflin.

Hofstede, G. (1980). Culture's consequences. Beverly Hills, CA: Sage.

Hu, L. T., \& Bentler, P. M. (1999). Cutoff criteria for fit indexes in covariance structure analysis: Conventional criteria versus new alternatives. Structural Equation Modeling: A Multidisciplinary Journal, 6(1), 1-55. https://doi.org/10.1080/10705519909540118

Huan, V. S., Quek, G. C. L., Yeo, L. S., Ang, R. P., \& Chong, W. H. (2012). How teacher-student relationship influenced student attitude towards teachers and school. The Asia-Pacific Education Researcher, 21(1), 151-159. Retrieved from http://link.springer.com/journal/volumesAndIssues/40299

Hughes, J. N., \& Kwok, O. (2006). Classroom engagement mediates the effect of teacher-student support on elementary students' peer acceptance: A prospective analysis. Journal of School Psychology, 43(6), 465-480. https://doi.org/10.1016/j.jsp.2005.10.001

Juvonen, J., \& Wentzel, K. (1996). Social motivation: Understanding children's school adjustment. New York., NY: Cambridge University Press. https://doi.org/10.1017/CBO9780511571190

Kagitcibasi, Ç. (1996). Family and human development across cultures: A view from the other side. Mahwah, NJ: Lawrence Erlbaum.

Karsenti, T., \& Thibert, G. (1994). The influence of gender on within-term changes in junior-college student motivation. Higher Education Abstracts, 30(2), 141. Retrived from http://karsenti.ca/pdf/scholar/ARS-karsenti-1-1995.pdf

Keen, M., \& Mahanty, S. (2006). Learning in sustainable natural resource management: Challenges and opportunities in the Pacific. Society and Natural Resources, 19(6), 497-513. https://doi.org/10.1080/08941920600663896

Kıran- Esen, B. (2003). Akran baskı düzeylerine ve cinsiyetlerine göre öğrencilerin risk alma davranışı ve okul başarılarının incelenmesi [Investigating students' risk-taking behavior and school achievement according to their peer pressure levels and gender]. Turkish Psychological Counseling and Guidance Journal, 2(20), 17-26. Retrieved from http://dergipark.ulakbim.gov.tr/tpdrd/issue/view/1058000041/showToc

Kissau, S. (2006). Gender differences in second language motivation: An investigation of micro- and macro-level influences. Canadian Journal of Applied Linguistics, 9(1), 73-96. Retrieved from https://journals.lib.unb.ca/index.php/CJAL/article/view/19755/21452 
Kline, R. B. (2005). Principles and practice of structural equation modeling. Newyork, NY: Guilford Publications, Inc.

Kolb, D. A. (1984). Experiential learning: Experience as the source of learning and development. Prentice Hall, Englewood Cliffs, NJ.

Krunke, H. M., \& Raufelder, D. (2014). What it means to be an adolescent teacher-and-peer-independent motivation type. Journal of Education and Learning, 3, 33-44. https://doi.org/10.5539/jel.v3n3p33

Ladd, G. W., Herald-Brown, S. L., \& Kochel, K. P. (2009). Peers and motivation. In K. R. Wentzel, \& A. Wigfield (Eds.), Handbook of motivation at school (pp. 323-348). New York, NY: Routledge.

Little, T. D., Cunningham, W. A., Shahar, G., \& Widaman, K. F. (2002). To parcel or not to parcel: Exploring the question and weighing the merits. Structural Equation Modeling, 9(2), 151-173. https://doi.org/10.1207/S15328007SEM0902_1

Meyer, L. H., McClure, J., Walkey, F., Weir, K. F., \& McKenzie, L. (2009). Secondary student motivation orientations and standards-based achievement outcomes. British Journal of Educational Psychology, 79(2), 273-293. https://doi.org/10.1348/000709908X354591

Nunnally, J. C., \& Bernstein, I. H. (1994). Psychometric theory. New York, NY: McGraw-Hill.

Pianta, R. C., Hamre, B., \& Stuhlman, M. (2003). Relationships between teachers and children. In W. Reynolds, \& G. Miller (Eds.), Handbook of psychology: Educational Psychology (pp. 199-234). New York, NY: Wiley. https://doi.org/10.1002/0471264385.wei0710

Raufelder, D., Drury, K., Jagenow, D., Hoferichter, F., \& Bulowski, W. (2013). Development and validation of the Relationship and Motivation (REMO) scale to assess students' perceptions of peers and teachers as motivators in adolescence. Learning and Individual Differences, 24, 182-189. https://doi.org/10.1016/j.lindif.2013.01.001

Reber, A. S., \& Reber, E. (2001). The penguin dictionary of psychology. London, United Kingdom: Penguin.

Reeve, J. (2006). Teachers as facilitators: What autonomy-supportive teachers do and why their students benefit. The Elementary School Journal, 106(3), 225-236. https://doi.org/10.1086/501484

Reindl, M., Berner, V. D., Scheunpflug, A., Zeinz, H., \& Dresel, M. (2015). Effect of negative peer climate on the development of autonomous motivation in mathematics. Learning and Individual Differences, 38, 68-75. https://doi.org/10.1016/j.lindif.2015.01.017

Ryan, R. M., \& Deci, E. L. (2000). Self-determination theory and the facilitation of intrinsic motivation, social $\begin{array}{llll}\text { development, and } \quad \text { american } & \text { Psychologist, }\end{array}$ https://doi.org/10.1037/0003-066X.55.1.68

Ryan, R. M., Stiller, J. D., \& Lynch, J. H. (1994). Representations of relationships to teachers, parents and friends as predictors of academic motivation and self-esteem. The Journal of Early Adolescence, 14(2), 226-249. https://doi.org/10.1177/027243169401400207

Saft, E. W., \& Pianta, R. C. (2001). Teachers' perceptions of their relationships with students: Effects of child age, gender, and ethnicity of teachers and children. School Psychology Quarterly, 16(2), 125-141. https://doi.org/10.1521/scpq.16.2.125.18698

Sarason, B. R., Sarason, I. G., \& Pierce, G. R. (1990). Traditional views of social support and their impact on assessment. In B. R. Sarason, I. G. Sarason, \& G. R. Sarason (Eds.), Social support: An interactional view (pp. 9-25). New York, NY: Wiley.

Schumacker, R. E., \& Lomax, R. G. (1996). A beginner's guide to structural equation modeling. New Jersey, NJ: Lawrence Erlbaum Associates, Inc.

Silver, R. B., Measelle, J. R., Armstrong, J. M., \& Essex M. J. (2005). Trajectories of classroom externalizing behavior: Contributions of child characteristics, family characteristics, and the teacher-child relationship during the school transition. Journal of School Psychology, 43(1), 39-60. https://doi.org/10.1016/j.jsp.2004.11.003

Skinner, E. A., \& Belmont, M. J. (1993). Motivation in the classroom: Reciprocal effects of teacher behavior and student engagement across the school year. Journal of Educational Psychology, 85(4), 571-581. https://doi.org/10.1037/0022-0663.85.4.571 
Steiger, J. H. (2007). Understanding the limitations of global fit assessment in structural equation modeling. Personality and Individual Differences, 42(5), 893-898. https://doi.org/10.1016/j.paid.2006.09.017

Sullivan, J. R., Ricco, C. A., \& Reynolds, C. R. (2008). Variations in students' school and teacher-related attitudes across gender, ethnicity and age. Journal of Instructional Psychology, 35(3), 296-305. Retrieved from https://www.questia.com/read/1G1-188351824/variations-in-students-school-and-teacher-related

Tabachnick, B. G., \& Fidell, L. S. (2007). Using multivariate statistics. Boston, MA: Allyn \& Bacon.

Thibert, G., \& Karsenti, T. (1996, April). Motivation profile of adolescent boys and girls: Gender differences throughout schooling. Paper presented at the Annual Conference of the American Educational Research Association, San Francisco, CA.

Thibert, G., \& Karsenti, T. (1998, April). The relationship between effective teachers and the motivational change of elementary-school boys and girls. Paper presented at the Annual Conference of the American Educational Research Association, San Diego, CA.

Trumbull, E., \& Rothstein-Fisch, C. (2011). The intersection of culture and achievement motivation. The School Community Journal, 21(2), 25-54.

Watt, H. M. G. (2004). Development of adolescents' self-perceptions, values and task perceptions according to gender and domain in 7th through 11th grade Australian students. Child Development, 75(5), 1556-1574. https://doi.org/10.1111/j.1467-8624.2004.00757.x

Weiner, B. (1972). Attribution theory, achievement motivation, and the educational process. Review of Educational Research, 42(2), 203-221. https://doi.org/10.3102/00346543042002203

Wentzel, K. R., Battle, A., Russell, S. L., \& Looney, L. B. (2010). Social supports from teachers and peers as predictors of academic and social motivation. Contemporary Educational Psychology, 35, 193-202. https://doi.org/10.1016/j.cedpsych.2010.03.002

Yılmaz, A. (2001). Sınıf içi öğrenci-öğrenci etkileşiminin öğrenme ve sosyal gelişim üzerine etkileri [The effects of student-student interaction in class on learning and social development]. Educational Administration: Theory and Practice, 7(1), 147-158. Retrieved from http://www.pegem.net/dosyalar/dokuman/1142-20110715115152-yimaz.pdf

Zhang, Y., Chen, C., Greenberger, E., \& Knowles, E. D. (2017). A cross-cultural study of punishment beliefs and decisions. Psychological Reports, 120(1), 5-24. https://doi.org/10.1177/0033294116679654

\section{Copyrights}

Copyright for this article is retained by the author(s), with first publication rights granted to the journal.

This is an open-access article distributed under the terms and conditions of the Creative Commons Attribution license (http://creativecommons.org/licenses/by/4.0/). 